\title{
Three-year analysis of zirconia implants used for single-tooth replacement and three-unit fixed dental prostheses: A prospective multicenter study
}

Balmer, Marc ; Spies, Benedikt C ; Vach, Kirstin ; Kohal, Ralf-Joachim ; Hämmerle, Christoph H F ; Jung, Ronald

\begin{abstract}
AIM The aim of the present investigation was to evaluate clinically and radiographically the outcome of zirconia oral implants after 3 years in function. MATERIALS AND METHODS In 60 patients in need of either a single-tooth replacement or a three-unit fixed dental prosthesis (FDP), a total of 71 one-piece zirconia implants were placed and immediately restored with temporary fixed prostheses. After a period of at least 2 months in the mandible and at least 4 months in the maxilla, zirconia-based reconstructions were cemented. The implants were clinically and radiologically examined at implant insertion, prosthetic delivery, at 6 months and then yearly up to 3 years. A linear mixed model was used to analyze statistically the influence of prognostic factors on changes in the marginal bone level. RESULTS Seventy-one implants (48 in the mandible, 23 in the maxilla) inserted in 60 patients were restored with 49 crowns and 11 FDP. One patient lost his implant after 5 weeks. Five patients with one implant each could not be evaluated after 3 years. Based on 55 patients with a total of 66 implants, the mean survival rate was $98.5 \%$ after 3 years in function. A statistically significant mean marginal bone loss $(0.70$ $\mathrm{mm} \pm 0.72 \mathrm{~mm}$ ) has been detected from implant insertion to the 3-year follow-up. The largest marginal bone loss occurred between implantation and prosthetic delivery $(0.67 \mathrm{~mm} \pm 0.56 \mathrm{~mm})$. After delivery, no statistically significant bone level change was observed $(0.02 \mathrm{~mm} \pm 0.59 \mathrm{~mm})$. None of the investigated prognostic factors had a significant influence on changes in the marginal bone level. CONCLUSIONS After 3 years in function, the investigated one-piece zirconia implant showed a high survival rate and a low marginal bone loss. The implant system was successful for single-tooth replacement and three-unit FDPs. Further investigations with long-term data are needed to confirm these findings.
\end{abstract}

DOI: https://doi.org/10.1111/clr.13115

Posted at the Zurich Open Repository and Archive, University of Zurich ZORA URL: https://doi.org/10.5167/uzh-153090

Journal Article

Accepted Version

Originally published at:

Balmer, Marc; Spies, Benedikt C; Vach, Kirstin; Kohal, Ralf-Joachim; Hämmerle, Christoph H F; Jung, Ronald E (2018). Three-year analysis of zirconia implants used for single-tooth replacement and three-unit fixed dental prostheses: A prospective multicenter study. Clinical Oral Implants Research, 29(3):290-299.

DOI: https://doi.org/10.1111/clr.13115 


\section{Three-year analysis of zirconia implants used for single tooth replacement and three-unit fixed dental prostheses. A prospective multicentre study}

Marc Balmer a, Benedikt Christopher Spies ${ }^{b}$, Kirstin Vach ${ }^{c}$, Ralf-Joachim Kohal ${ }^{b}$ Christoph H F Hämmerle ${ }^{a}$ Ronald E Jung ${ }^{a}$

a Clinic of Fixed and Removable Prosthodontics and Dental Material Science, Center of Dental Medicine, University of Zurich, Switzerland

b Department of Prosthetic Dentistry, Center for Dental Medicine, Medical Center University of Freiburg, Faculty of Medicine, University of Freiburg, Germany ${ }^{c}$ Institute for Medical Biometry and Statistics, Center for Medical Biometry and Medical Informatics, University Medical Center Freiburg, Germany

Key words: ceramic, dental implants, human, Zirconia, clinical, bone, osseointegration

Running title: Three-years analysis of zirconia implants

Address for correspondence: $\quad$ Dr. med. dent. Marc Balmer

Clinic of Fixed and Removable Prosthodontics and Dental Material Science

Center of Dental Medicine, University of Zurich

Plattenstrasse 11

$\mathrm{CH}-8032$ Zurich, Switzerland

Phone: +4144634 3258

Fax: +41446344305

e-mail: marc.balmer@zzm.uzh.ch 


\section{Abstract}

Aim: The aim of the present investigation was to evaluate clinically and radiographically the outcome of zirconia oral implants after 3 years in function.

Materials and Methods: In 60 patients in need of either a single tooth replacement or a three-unit FDP a total of 71 one-piece zirconia implants were placed and immediately restored with temporary fixed prostheses. After a period of at least 2 months in the mandible and at least 4 months in the maxilla, zirconia-based reconstructions were cemented. The implants were clinically and radiologically examined at implant insertion, prosthetic delivery, at 6 months and then yearly up to 3 years. A linear mixed model was used to analyse statistically the influence of prognostic factors on changes in the marginal bone level.

Results: 71 implants (48 in the mandible, 23 in the maxilla) inserted in 60 patients were restored with 49 crowns and 11 FDP. One patient lost his implant after 5 weeks. Five patients with 1 implant each could not be evaluated after 3 years. Based on 55 patients with a total of 66 implants, the mean survival rate was $98.5 \%$ after 3 years in function.

A statistically significant mean marginal bone loss $(0.70 \mathrm{~mm} \pm 0.72 \mathrm{~mm})$ has been detected from implant insertion to the 3-year follow-up. The largest marginal bone loss occurred between implantation and prosthetic delivery $(0.67 \mathrm{~mm} \pm 0.56 \mathrm{~mm})$. After delivery, no statistically significant bone level change was observed $(0.02 \mathrm{~mm} \pm$ $0.59 \mathrm{~mm}$ ). None of the investigated prognostic factors had a significant influence on changes in the marginal bone level. 
Conclusions: After 3 years in function, the investigated one-piece zirconia implant showed a high survival rate and a low marginal bone loss. The implant system was successful for single tooth replacement and three-unit FDPs. Further investigations with long-term data are needed to confirm these findings. 


\section{Introduction}

Endosseous screw-type implants offer a good opportunity to restore missing or lost teeth. Nowadays, there are a variety of different implant-systems and implants made of different materials available on the dental market. Regarding the material, implants from commercially pure titanium present the largest group of the used implants in the last decades. Based on various systematic reviews titanium implants reveal high implant survival and success rates over a long time period. Jung et al. (2012) reported in a systematic review a survival rate of $97.2 \%$ at 5 years and $95.2 \%$ at 10 years for commercially available titanium implants supporting single crowns (Jung et al. 2012). The reported survival rate of implants supporting FDPs was 95.6\% after 5 years and $93.1 \%$ after 10 years (Jung, Zembic, Pjetursson, Zwahlen, Thoma, 2012).

However, there are a number of patients demanding for metal-free solutions for implants and prosthetics. In addition, a few preclinical studies showed that a certain amount of titanium could be found in the tissues around dental implants (Addison, et al., 2012; Bianco, Ducheyne, Cuckler, 1996). Moreover, there is some evidence that metals in the oral cavity undergo corrosion through an electrochemical redox

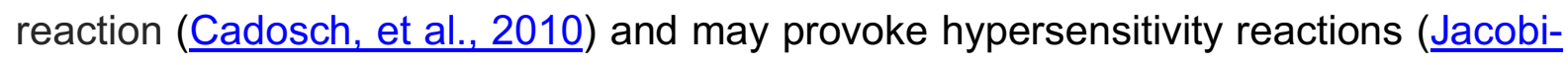
Gresser, Huesker, Schutt, 2013) or even allergic reactions (Tschernitschek, Borchers, Geurtsen, 2005). Even though its estimated prevalence is low (0.6\%), Ti allergy can be detected in dental implant patients (Sicilia, et al., 2008).

In order to overcome these possible, unwelcomed reactions, zirconia implants have been investigated. They show a high biocompatibility, good physical characteristics and a tooth-like colour. In vitro evaluations confirmed that zirconia is not cytotoxic and is not able to generate mutations of the cellular genome (Covacci, et al., 1999). In vivo studies reported that the osseointegration of zirconia is similar to 
commercially pure titanium (Kohal, Weng, Bachle, Strub, 2004; Manzano, Herrero, Montero, 2014) and histological investigations have shown that particularly in the early wound healing zirconia led to an increased proliferation of osteoblasts (Hisbergues, Vendeville, Vendeville, 2009). Based on the excellent mechanical properties in particular a high flexural strength (900-1200 MPa), high fracture toughness (7-10 MPa m ${ }^{1 / 2}$ and a fairly high hardness (1200 HV0.1) yttria-stabilized zirconia is an appropriate biomaterial for dental implants (Piconi, Maccauro, 1999). Zirconia has proven its value as a preferred esthetic material in challenging gingival conditions. Jung et al. (2007) have shown that all-ceramic abutments led to less change in color in a thin gingival biotype than titanium abutments (Jung, Sailer, Hammerle, Attin, Schmidlin, 2007).

On the other hand, zirconia can show signs of aging under certain circumstances, which has been described as low temperature degradation (Kobayashi, Kuwajima, Masaki, 1981). Furthermore, one study showed that zirconium can also be found around zirconia implants (Cionca, Hashim, Meyer, Michalet, Mombelli, 2016). Whether or not this has an influence on the long-term outcomes of endosseous ceramic implants, remains to be clarified. Although ceramic implants are presently used for several indications, a recently published systematic review (Pieralli, Kohal, Jung, Vach, Spies, 2017) stated that few clinical reports on zirconia ceramic implants are available with an investigation time of three years and more.

Therefore, the aim of the present investigation was to evaluate clinically and radiographically the long-term safety and efficiency of zirconia oral implants for single tooth replacement and three-unit fixed dental prostheses (FDPs) after 3 years in function. 


\section{Materials and Methods}

\section{Study design}

The study was designed as a prospective cohort investigation according to Dekkers et al. (2012) (Dekkers, Egger, Altman, Vandenbroucke, 2012). It was performed at two investigation centers: at the Department of Prosthetic Dentistry, Center for Dental Medicine, Medical Center - University of Freiburg, Faculty of Medicine, Freiburg, Germany and at the Clinic of Fixed and Removable Prosthodontics and Dental Material Science, Center of Dental Medicine, University of Zurich, Switzerland. Both local ethical committees ((Ethics Commission, Medical Center University of Freiburg, Freiburg (241/08) and (Ethic Committee of the Canton of Zurich (StV 08/10)) gave their approval and the study was conducted in full accordance with the World Medical Association Declaration of Helsinki. All patients were thoroughly informed about the study protocol and have signed an inform consent form prior to their inclusion.

\section{Participants}

Sixty patients in need of either exact one single tooth replacement or exact one implant supported three-unit fixed dental prosthesis were consecutively included. The detailed inclusion and exclusion criteria have been outlined already in a previous study (Jung, et al., 2016). In brief, the patients were only included if they were between 20 and 70 years old and in good general condition. The implant site had to be free of infection or extraction remnants and had to contain sufficient bone for the placement of an implant with a diameter of at least $4 \mathrm{~mm}$ and a length of $8 \mathrm{~mm}$. The patients were excluded if there were any general medical findings, which did not permit the surgical procedure. Further exclusion criteria were the intake of medication that is known to interfere with the objectives of the study, pregnancy, 
signs of severe bruxism, a reported alcohol or drug abuse or nicotine abuse of more than 15 cigarettes per day. Also, the need for primary bone augmentation at the implantation site was an exclusion criterion; however, a simultaneous minor bone augmentation procedure was allowed to cover any exposed rough surfaces of the implant.

\section{Materials}

The presently investigated ceramic implant was a commercially available one-piece zirconia screw-type implant (ceramic.implant; vitaclinical, VITA Zahnfabrik, Bad Säckingen, Germany). The endosseous part is constructed in a cylindric-conical geometrical form. The available implant lengths were 8, 10, 12 and $14 \mathrm{~mm}$ and the available diameters $4.0,4.5$ and $5.5 \mathrm{~mm}$.

Regarding the material composition, surface roughness and processing steps, please refer to Fischer et al. (2016) (Fischer, Schott, Martin, 2016).

\section{Interventions}

A late implant insertion (3 months after tooth extraction) was recommended; under optimal circumstances a delayed implant insertion (6-8 weeks after extraction) was possible (Fig. 1a). For the placement of the implants, a mucoperiostal flap was raised as far as necessary under local anesthesia (Ubistesin ${ }^{\mathrm{TM}}$ forte) (Fig. 1b). The implants were placed according to the manufacture's recommendations in a prosthetically correct position and angulation (Fig. 1c). If required, guided bone regeneration was performed with xenogenic bone substitutes (BioOss ${ }^{\circledR}$ Spongiosa Granules, particle size 0.25-1.0 mm; Geistlich Pharma AG, Wolhusen, Switzerland) (Fig. 1d) and a collagen membrane (BioGide ${ }^{\circledR}$ Membrane; Geistlich Pharma AG) to cover the rough implant surface or to compensate deficiencies in the bony contour 
(Fig. 1e). The flap was sutured for a transmucosal healing and the implants were immediately restored with prefabricated provisional reconstructions made from PMMA (Fig. 1f). The occlusion and lateral articulation was carefully checked and adjusted, i.e. contacts in static or dynamic occlusion were removed.

\section{Postoperative treatment}

Patients were instructed to not mechanically clean the operation field but to rinse twice a day with $0.2 \%$ chlorhexidine aqueous solution. They were given antibiotic prophylaxis on the day of surgery and thereafter three times a day for 5 days $(750 \mathrm{mg}$ Clamoxy|® in Zurich; 300mg clindamycin in Freiburg) after implant placement. Analgetics (500 mg Mefenacid in Zurich; $400 \mathrm{mg}$ Ibuprofen in Freiburg) were dispensed and taken according to the individual requirements. Sutures were removed 10 days after the surgical intervention.

\section{Prosthetic insertion and follow-ups}

The final prosthetic restoration was inserted at the earliest 2 months after implant placement in the mandible and 4 months in the maxilla. Both types of restorations, the implant supported SC and the implant supported three unit FDPs were manufactured from a zirconia framework (VITA In-Ceram YZ), which was subsequently veneered (VITA VM9) and adhesively cemented with a dual-curing cement (RelyX Unicem Aplicap; 3M Espe) (Spies, Kohal, Balmer, Vach, Jung, 2017) (Fig. 1g).

The implants were examined at baseline (implant insertion), at the placement of the restoration, at 6 months and then yearly up to 3 years (Fig.2a-c). 


\section{Clinical and radiographic examination}

At each visit, soft tissue parameters in terms of Probing depth (PD), Marginal soft tissue level (ML), Clinical attachment level (CAL), Plaque control record (Pcr) and Bleeding on probing (BoP) were recorded at 4 positions of the implants and neighboring teeth. One examiner per investigation center performed the measurements. Examiner alignment and calibration have been performed prior to the examinations. PD, ML, CAL and the presence of Plaque were recorded with a periodontal probe (PCP 12 Hu Friedy, Rotterdam, Netherlands) and the reference for the assessment of CAL und ML was the margin of the implant-crown / cementoenamel junction. For the analyses of PD, ML and CAL the four implant- / tooth-sites (mesial, buccal, distal lingual) were averaged. The size of the gingival papilla (Index according to Jemt (Jemt, 1997)) was recorded between the implants and neighboring teeth.

Standardized periapical radiographs were taken at implant insertion, at the placement of the restoration, at 1 year and at 3 years with an individual acrylic radiographic film holder (Fig 3a-d and 4a-d). Radiographs were imported in an open source image-processing program (ImageJ, National Institutes of Health, Bethesda, USA) and calibrated to measure the peri-implant bone level at each timepoint. Marginal bone loss was calculated as difference between baseline (implant placement) and subsequent follow-ups.

During the evaluation of the radiographic outcome at the 3-year follow-up, the authors detected a calibration error (incorrect distance of implant threads) for the measurements up to the 1-year follow-up. This previously published data of the same cohort (Jung, et al., 2016) were recalculated and subsequently corrected for the present publication. 


\section{Statistical analysis}

The statistical analysis was performed at the University of Freiburg, Center for Medical Biometry and Medical Informatics, Institute for Medical biometry and Statistics, Freiburg, Germany.

Sample size calculation has been performed as previously described in detail (Jung. et al., 2016). For the analysis of the mean marginal bone level linear mixed models with random intercept were used to take within-subject dependencies (i.e. 2 implants within 1 patient) into account. For the clinical parameters Wilcoxon signed-rank tests were used to compare both results of implants and corresponding teeth per time point and results between 0 and 36 months within implants and teeth, respectively. The calculations were performed with the statistical software STATA 14.2 (StataCorp LT, College Station, TX, USA). The probability level for statistical significance was set to $p<0.05$.

\section{Results}

\section{Patient demographics and baseline characteristics}

Pretreatment examination was performed at 63 patients at one of the two investigation centers. Three patients had at least one violation of inclusion/exclusion criteria and were therefore excluded from the analysis. Two of these three patients received more than exactly one single tooth replacement and in one patient no implant could be placed due to insufficient bone volume.

The remaining 60 patients (30 male / 30 female) had a mean age of 48.1 years \pm 13.0 at the pretreatment examinations. They received a total of 71 implants $(23$ in the upper jaw / 48 in the lower jaw) (Table 1 and 2) between November 2009 and April 2011. Five implants in the maxilla and 6 in the mandible were placed with a 
simultaneous guided bone augmentation procedure. Since one patient lost his implant 5 weeks after implantation due to a missing osseointegration, the implants were restored with $48 \mathrm{SC}$ and 11 FDPs.

At the 3-year follow-up after final prosthetic restoration, 54 patients with a total of 65 implants could be evaluated. Five patients with one implant each did not show up for different reasons (one moved away; one missed the appointment; three more patients refused further participation). As described above, one patient with one implant dropped out short time after implant placement.

Analysis of the marginal bone loss (primary endpoint)

The mean marginal bone loss from implant insertion to the 3-year follow-up after the final prosthetic restoration was $0.70 \mathrm{~mm} \pm 0.72 \mathrm{~mm}$. Table 3 shows the marginal bone loss from baseline to each evaluated timepoint. The change of mean marginal bone level was statistically significant $(p<0.001)$ between implantation and the 3 -year follow-up. The largest marginal bone loss occurred between implantation and the insertion of the final restoration $(0.67 \mathrm{~mm} \pm 0.56 \mathrm{~mm})$. From delivery of the restorations to the 3-year follow-up, no further statistically significant bone loss was observed $(0.02 \mathrm{~mm} \pm 0.59 \mathrm{~mm} ; \mathrm{p}=0.66)$.

The frequency distribution for mean marginal bone level changes was as follows: $13 \%$ of the implants gained marginal bone, while $56 \%$ lost less than $1 \mathrm{~mm}, 22 \% 1$ $\mathrm{mm}$ to $1.5 \mathrm{~mm}, 6 \% 1.5 \mathrm{~mm}$ to $2 \mathrm{~mm}$ and $3 \%$ more than $2 \mathrm{~mm}$ of marginal bone. None of the investigated prognostic factors (center, jaw, type of reconstruction, implant diameter and length) had a significant influence on changes in the marginal bone level, except the baseline value of mean initial insertion depth of the implants $(p<0.001)($ Table 4$)$.

The estimator for "insertion depth" indicates, that a change in insertion depth at 
implantation of $1 \mathrm{~mm}$ leads to a change of $0.695 \mathrm{~mm}$ marginal bone loss after 3 years. The estimated difference in mean marginal bone loss is about a value of 0.152 larger for Zurich than for Freiburg, about 0.390 units smaller for the upper jaw than for the lower jaw and 0.326 units smaller for a bridge than for a single tooth. For an implant diameter of 4.5 and $5.5 \mathrm{~mm}$ the difference is about 0.065 and 0.275 units larger than for diameter $4.0 \mathrm{~mm}$, respectively. For an implant length of $10 \mathrm{~mm}$ the difference is about 0.156 units smaller and for an implant length of 12 and $14 \mathrm{~mm}$ about 0.226 and 0.282 units larger than for length of $8 \mathrm{~mm}$, respectively.

Analysis of secondary endpoint (survival rate of the implants)

During the observation time, one implant in the mandible failed 5 weeks after insertion. In addition, 5 implants in different patients could not be evaluated because the patients did not show up to the 3-year follow-up. Based on 55 patients with a total of 66 implants, the mean survival rate was $98.5 \%$ (95\% Cl: $91.8 \%-99.9 \%)$ after 3 years in function.

\section{Clinical measurements}

At each visit, plaque frequency was recorded at 4 sites of the implants and adjacent teeth (Table 5). At prosthetic insertion the frequencies of plaque around implants $(11.8 \%)$ and teeth $(21.0 \%)$ was at the lowest level. This value increased for both groups between prosthetic insertion and the 6-month follow-up and remained on a relatively high level up to the 3-year follow-up (implants: $20.8 \%$, teeth $41.4 \%$ ). At each timepoint plaque frequencies were significantly lower at implant sites compared to teeth.

At implant sites, the mean Probing depth (Table 6) increased from $2.71 \mathrm{~mm}$ at prosthetic delivery to $3.52 \mathrm{~mm}$ after 3 years. Wilcoxon signed-rank test applied to the 
differences comparing 36 months with baseline showed significant changes in PD on patient level for implants $(p<0.001)$ but not for teeth. The mean PD at the adjacent teeth changed only from $2.53 \mathrm{~mm}$ to $2.54 \mathrm{~mm}$ during the observation period. The difference at each follow-up between implants and teeth was statistically significant $(p<0.0001)$

The frequency of Bleeding on probing (BoP) (Table 7) was significantly higher during the whole observation time for implants compared to the neighboring teeth except at prosthetic insertion. The largest increase could be observed between prosthetic delivery and the 6-month follow-up for both groups. After 3 years, BOP for implants was $40.8 \%$, which is about 2 times higher than for teeth $(23.2 \%)$.

Mean marginal soft tissue level (Table 8) decreased from $0.7 \mathrm{~mm}$ to $0.65 \mathrm{~mm}$ at implants. At adjacent teeth there was nearly no change in mean marginal soft tissue level $(0.01 \mathrm{~mm})$, but the Wilcoxon signed-rank test (baseline vs 36 month) showed significant changes in ML on patient level $(p=0.047)$.

The Clinical attachment level (CAL) (Table 9) around the implants at prosthetic insertion was $2.76 \mathrm{~mm}$ and $3.14 \mathrm{~mm}$ at the teeth. Until the 3-year follow-up, changes per patient in CAL were not significant at implant sites $(p=0.523)$ and around teeth $(p=0.052)$.

\section{Discussion}

The present multicenter prospective cohort investigations evaluated the mean marginal bone loss, survival rate and peri-implant soft tissue conditions of 71 zirconia implants placed in 60 healthy patients after 3 years in function. Presently, only few clinical reports on zirconia ceramic implants are available with an 
investigation time of three years and more (Pieralli, et al., 2017). Therefore, the present investigation adds to the scientific knowledge regarding these implants.

Long-term stable conditions of osseointegration around implants particularly in respect to marginal bone loss have been identified as success criteria for longevity for implants (Albrektsson, Zarb, Worthington, Eriksson, 1986; Roos, et al., 1997). The present investigation showed a mean marginal bone loss of $0.70 \mathrm{~mm}$ after 3 years with the maximum loss between the interval of implantation and prosthetic delivery $(0.67 \mathrm{~mm})$.

Another recently published prospective clinical trial with a similar study design (Spies, Balmer, Patzelt, Vach, Kohal, 2015) investigated 53 immediately temporized one-piece alumina-toughened zirconia implants over an observation time of 3 years after prosthetic delivery. The authors reported a similar mean marginal bone loss over the 3 years. As in the present study, they observed the greatest amount of bone loss between implantation and prosthetic insertion $(0.70 \mathrm{~mm})$ : No further statistically significant bone loss up to the 3-year follow-up $(0.79 \mathrm{~mm})$ occurred. The finding of a pronounced MBL in the first 6 months after implant placement is in line with another study reporting on marginal bone loss over time for zirconia implants up to 4 years (Borgonovo, et al., 2013).

In a recently published systematic review (Pieralli, et al., 2017), the authors stated that no further meta-analysis for MBL of zirconia implants except for 12 months data could be performed due to the lack of long-term data. Their analysis after 12 months resulted in a MBL of $0.79 \mathrm{~mm}$, which is slightly larger as observed in the present study $(0.60 \mathrm{~mm})$. However, other clinical studies analyzing MBL around zirconia implants reported results after 3 years of $0.13 \mathrm{~mm}$ (Brull, van Winkelhoff, Cune, $\underline{2014}$ ) and $0.79 \mathrm{~mm}$ (Spies, et al., 2015), of $1.63 \mathrm{~mm}$ after 4 years (Borgonovo, et al., $\underline{2013}$ ) and of $1.23 \mathrm{~mm}$ after 5 years (Grassi, et al., 2015). Considering the fact that 
after an initial remodeling, no further significant marginal bone loss could be detected and based on MBL after 3 years in this present study it can be concluded that marginal bone level around zirconia implants might be stable over a longer period of time.

Although in the present investigation the mean marginal bone loss amounted only to $0.70 \mathrm{~mm}$, it has to be revealed that 2 out of 65 implants had a MBL $\geq 2 \mathrm{~mm}$ and 4 implants showed a MBL between 1.5 and $2 \mathrm{~mm}$.

In the present investigation none of the evaluated prognostic factors (center, jaw, type of reconstruction, implant diameter and length) had a significant influence on MBL except for the baseline value insertion depth. The small $p$-value $(p<0.001)$ for marginal bone level at implantation in the mixed effect model should be interpreted cautiously. In this change from baseline analysis, the baseline value was only considered for adjustment according to EMA guidance "Points to consider on Adjustment for Baseline Covariates" (European Agency for the Evaluation of Medical Products, CPMP/EWP/2863/99)."

One implant out of 71 failed in our investigation 5 weeks after implantation due to a loss of osseointegration. Since 3 implants couldn't be evaluated at the 1-year followup and 5 at the 3 -year follow-up, the survival rate was $98.6 \%$ after 1 year and $98.5 \%$ after 3 years, respectively. In a recently published systematic review (Hashim, Cionca, Courvoisier, Mombelli, 2016), the one-year overall survival rate of (one- and two-piece) zirconia implants was calculated with $92 \%(95 \% \mathrm{Cl}: 87 \%-95 \%)$. Due to the limited observation periods of the included studies, no meta-analysis could be performed for later timepoints. The authors also reported a tendency towards early failure of one-piece implants with a calculated early failure rate at $77 \%$ (95\% Cl: $56 \%$ - 90\%). However, no further loss of implants could be detected up to the 3-year follow-up. 
At each follow up, soft tissue parameters were recorded of the implants and neighboring teeth. Bleeding on probing was significantly more frequent after prosthetic delivery over the whole observation time for implants in comparison to teeth, although the plaque frequency was significantly lower at implant sites compared to teeth. As described in the literature, BOP is considered a clinical key measure to distinguish between disease and peri-implant health (Jepsen, et al., $\underline{2015}$ ) and is always present with peri-implant disease (Zitzmann, Berglundh, 2008). Nevertheless, peri-implantitis is characterized by changes in the marginal bone level in conjunction with Bleeding on probing with or without concomitant deepening of Probing depth (Lang, Berglundh, Working Group 4 of Seventh European Workshop on, 2011). In this study no significant changes in marginal bone level could be found after delivery of the restorations. However, the analyses showed significant changes in PD $(p<0.001)$ on patient level and an increase in mean PD at implant sites but not for teeth.

Interestingly, the analysis for CAL at implant sites demonstrated no significant differences to baseline after 3 years although $P D$ increased over time and $M L$ remained stable. A possible reason behind this is that $P D, M L$ and $C A L$ have been measured individually. CAL was not calculated as the mathematically sum of PD and ML which could lead to a small discrepancy to the measured value. However the Clinical attachment level did not change significantly over the 3 years, neither for implants nor for teeth, indicating stable soft tissue conditions around the investigated implants.

The present study was designed as a prospective cohort investigation without a control group. This might be a major limitation of the study and does not allow a direct comparison within the same cohort to titanium implants. However, it allowed us to collect more data and to gain clinical experience with a rather new implant 
material. An affirmative factor is, that the study was performed in two investigational centers, which reduces the center effect on the results.

In addition, 11 out of 71 implants of the present study were placed with a simultaneous bone augmentation procedure using a xenogenic bone substitute. This can be another limitation of the present study because bovine bone substitute shows a radiopacity similar to human bone. It is therefore often difficult to distinguish from pristine bone and could have had an influence on the radiographical measurements. To ensure a standardized analysis of the periimplant bone loss, we measured the highest bone-to-implant-contact without differentiating between human bone and substitute.

In conclusion, the investigated one-piece zirconia implant showed a high survival rate and a low marginal bone loss after 3 years in function. Therefore, the implant can be regarded as successful for single tooth replacement and three-unit FDPs. Nevertheless, further investigations with long-term data are still needed to confirm these positive findings.

\section{Acknowledgement}

This investigation was supported by a grant from VITA Zahnfabrik - H. Rauter GmbH \& Co. KG, Bad Säckingen, Germany.

\section{Figure legends}

Fig. 1 Implant insertion and prosthetic delivery:
a)
initial Situation 
b) mucoperiostal flap

c) implant insertion

d) guided bone regeneration

e) collagen membrane

f) immediate provisional reconstruction

g) prosthetic delivery

Fig 2 Follow-ups:
a)
1 year in function
b) 2 years in function
c) 3 years in function

Fig. 3a-d Radiographic image (SC):

(a) after implantation and provisional reconstruction

(b) at prosthetic delivery

(c) after 1 year in function

(d) after 3 year in function

Fig. 4 a-d Radiographic image (FDP):

(a) after implantation and provisional reconstruction

(b) at prosthetic delivery

(c) after 1 year in function

(d) after 3 year in function

\section{References}

Addison, O., Davenport, A. J., Newport, R. J., Kalra, S., Monir, M., Mosselmans, J. F., Proops, D. \& Martin, R. A. (2012). Do 'passive' medical titanium surfaces 
deteriorate in service in the absence of wear? J R Soc Interface 9: 3161-3164. doi:10.1098/rsif.2012.0438

Albrektsson, T., Zarb, G., Worthington, P. \& Eriksson, A. R. (1986). The long-term efficacy of currently used dental implants: a review and proposed criteria of success. International Journal of Oral and Maxillofacial Implants 1:11-25.

Bianco, P. D., Ducheyne, P. \& Cuckler, J. M. (1996). Local accumulation of titanium released from a titanium implant in the absence of wear. Journal of Biomedical Materials Research 31: 227-234. doi:10.1002/(SICI)10974636(199606)31:2\&lt;227::AID-JBM9\&gt;3.0.CO;2-P

Borgonovo, A. E., Censi, R., Vavassori, V., Dolci, M., Calvo-Guirado, J. L., Delgado Ruiz, R. A. \& Maiorana, C. (2013). Evaluation of the success criteria for zirconia dental implants: a four-year clinical and radiological study. International journal of dentistry 2013: 463073. doi:10.1155/2013/463073

Brull, F., van Winkelhoff, A. J. \& Cune, M. S. (2014). Zirconia dental implants: a clinical, radiographic, and microbiologic evaluation up to 3 years. International Journal of Oral and Maxillofacial Implants 29: 914-920. doi:10.11607/jomi.3293

Cadosch, D., Al-Mushaiqri, M. S., Gautschi, O. P., Meagher, J., Simmen, H. P. \& Filgueira, L. (2010). Biocorrosion and uptake of titanium by human osteoclasts. Journal of biomedical materials research. Part A 95: 1004-1010. doi:10.1002/jbm.a.32914

Cionca, N., Hashim, D., Meyer, J., Michalet, S. \& Mombelli, A. (2016). Inductively coupled plasma mass spectrometry detects zirconium and titanium elements in periimplant mucosa. Journal of Dental Research 95: Spec Iss B, 995.

Covacci, V., Bruzzese, N., Maccauro, G., Andreassi, C., Ricci, G. A., Piconi, C., Marmo, E., Burger, W. \& Cittadini, A. (1999). In vitro evaluation of the mutagenic and carcinogenic power of high purity zirconia ceramic. Biomaterials 20: 371-376.

Dekkers, O. M., Egger, M., Altman, D. G. \& Vandenbroucke, J. P. (2012). Distinguishing case series from cohort studies. Annals of Internal Medicine 156: 3740. doi:10.7326/0003-4819-156-1-201201030-00006

Fischer, J., Schott, A. \& Martin, S. (2016). Surface micro-structuring of zirconia dental implants. Clinical Oral Implants Research 27: 162-166. doi:10.1111/clr.12553

Grassi, F. R., Capogreco, M., Consonni, D., Bilardi, G., Buti, J. \& Kalemaj, Z. (2015). Immediate occlusal loading of one-piece zirconia implants: five-year radiographic and clinical evaluation. International Journal of Oral and Maxillofacial Implants 30: 671680. doi:10.11607/jomi.3831 
Hashim, D., Cionca, N., Courvoisier, D. S. \& Mombelli, A. (2016). A systematic review of the clinical survival of zirconia implants. Clinical Oral Investigations 20: 1403-1417. doi:10.1007/s00784-016-1853-9

Hisbergues, M., Vendeville, S. \& Vendeville, P. (2009). Zirconia: Established facts and perspectives for a biomaterial in dental implantology. Journal of biomedical materials research. Part B, Applied biomaterials 88: 519-529. doi:10.1002/jbm.b.31147

Jacobi-Gresser, E., Huesker, K. \& Schutt, S. (2013). Genetic and immunological markers predict titanium implant failure: a retrospective study. International Journal of Oral and Maxillofacial Surgery 42: 537-543. doi:10.1016/j.jjom.2012.07.018

Jemt, T. (1997). Regeneration of gingival papillae after single-implant treatment. International Journal of Periodontics and Restorative Dentistry 17: 326-333.

Jepsen, S., Berglundh, T., Genco, R., Aass, A. M., Demirel, K., Derks, J., Figuero, E., Giovannoli, J. L., Goldstein, M., Lambert, F., Ortiz-Vigon, A., Polyzois, I., Salvi, G. E., Schwarz, F., Serino, G., Tomasi, C. \& Zitzmann, N. U. (2015). Primary prevention of peri-implantitis: managing peri-implant mucositis. Journal of Clinical Periodontology 42 Suppl 16: S152-157. doi:10.1111/jcpe.12369

Jung, R. E., Grohmann, P., Sailer, I., Steinhart, Y. N., Feher, A., Hammerle, C., Strub, J. R. \& Kohal, R. (2016). Evaluation of a one-piece ceramic implant used for single-tooth replacement and three-unit fixed partial dentures: a prospective cohort clinical trial. Clinical Oral Implants Research 27: 751-761. doi:10.1111/clr.12670

Jung, R. E., Sailer, I., Hammerle, C. H., Attin, T. \& Schmidlin, P. (2007). In vitro color changes of soft tissues caused by restorative materials. International Journal of Periodontics and Restorative Dentistry 27: 251-257.

Jung, R. E., Zembic, A., Pjetursson, B. E., Zwahlen, M. \& Thoma, D. S. (2012). Systematic review of the survival rate and the incidence of biological, technical, and aesthetic complications of single crowns on implants reported in longitudinal studies with a mean follow-up of 5 years. Clinical Oral Implants Research 23 Suppl 6: 2-21. doi:10.1111/j.1600-0501.2012.02547.x

Kobayashi, K., Kuwajima, H. \& Masaki, T. (1981). Phase-Change and MechanicalProperties of Zro2-Y203 Solid Electrolyte after Aging. Solid State lonics 3-4: 489-493. doi:Doi 10.1016/0167-2738(81)90138-7

Kohal, R. J., Weng, D., Bachle, M. \& Strub, J. R. (2004). Loaded custom-made zirconia and titanium implants show similar osseointegration: an animal experiment. Journal of Periodontology 75: 1262-1268. doi:10.1902/jop.2004.75.9.1262

Lang, N. P., Berglundh, T. \& Working Group 4 of Seventh European Workshop on, P. (2011). Periimplant diseases: where are we now?--Consensus of the Seventh 
European Workshop on Periodontology. Journal of Clinical Periodontology 38 Suppl 11: 178-181. doi:10.1111/j.1600-051X.2010.01674.x

Manzano, G., Herrero, L. R. \& Montero, J. (2014). Comparison of clinical performance of zirconia implants and titanium implants in animal models: a systematic review. International Journal of Oral and Maxillofacial Implants 29: 311320. doi:10.11607/jomi.2817

Piconi, C. \& Maccauro, G. (1999). Zirconia as a ceramic biomaterial. Biomaterials 20: 1-25. doi:Doi 10.1016/S0142-9612(98)00010-6

Pieralli, S., Kohal, R. J., Jung, R. E., Vach, K. \& Spies, B. C. (2017). Clinical Outcomes of Zirconia Dental Implants: A Systematic Review. Journal of Dental Research 96: 38-46. doi:10.1177/0022034516664043

Roos, J., Sennerby, L., Lekholm, U., Jemt, T., Grondahl, K. \& Albrektsson, T. (1997). A qualitative and quantitative method for evaluating implant success: a 5-year retrospective analysis of the Branemark implant. International Journal of Oral and Maxillofacial Implants 12: 504-514.

Sicilia, A., Cuesta, S., Coma, G., Arregui, I., Guisasola, C., Ruiz, E. \& Maestro, A. (2008). Titanium allergy in dental implant patients: a clinical study on 1500 consecutive patients. Clinical Oral Implants Research 19: 823-835. doi:10.1111/j.1600-0501.2008.01544.x

Spies, B. C., Balmer, M., Patzelt, S. B., Vach, K. \& Kohal, R. J. (2015). Clinical and Patient-reported Outcomes of a Zirconia Oral Implant: Three-year Results of a Prospective Cohort Investigation. Journal of Dental Research 94: 1385-1391. doi:10.1177/0022034515598962

Spies, B. C., Kohal, R. J., Balmer, M., Vach, K. \& Jung, R. E. (2017). Evaluation of zirconia-based posterior single crowns supported by zirconia implants: preliminary results of a prospective multicenter study. Clinical Oral Implants Research 28: 613619. doi:10.1111/clr.12842

Tschernitschek, H., Borchers, L. \& Geurtsen, W. (2005). Nonalloyed titanium as a bioinert metal--a review. Quintessence International 36: 523-530.

Zitzmann, N. U. \& Berglundh, T. (2008). Definition and prevalence of peri-implant diseases. Journal of Clinical Periodontology 35: 286-291. doi:10.1111/j.1600051X.2008.01274.X 


\section{Tables}

Table 1: Implant distribution

\begin{tabular}{|l|c|c|c|c|c|c|c|c|c|c|c|c|c|l|l|}
\hline FDI & 17 & 16 & 15 & 14 & 13 & 12 & 11 & 21 & 22 & 23 & 24 & 25 & 26 & 27 & Total \\
\hline Upper Jaw & 1 & 1 & 4 & 5 & 1 & 0 & 1 & 0 & 0 & 0 & 2 & 5 & 3 & 0 & $\mathbf{2 3}$ \\
\hline Lower Jaw & 4 & 11 & 4 & & & & & 1 & & & 2 & 7 & 13 & 6 & $\mathbf{4 8}$ \\
\hline FDI & 47 & 46 & 45 & 44 & 43 & 42 & 41 & 31 & 32 & 33 & 34 & 35 & 36 & 37 & $\mathbf{7 1}$ \\
\hline
\end{tabular}

Table 2: Implant characteristics

\begin{tabular}{|c|c|c|c|c|c|c|c|}
\hline & \multicolumn{3}{|c|}{ implant diameter } & \multicolumn{4}{c|}{ implant length } \\
\cline { 2 - 8 } & 4.0 & 4.5 & 5.5 & 8 & 10 & 12 & 14 \\
\hline Upper Jaw & 11 & 11 & 1 & 6 & 8 & 8 & 1 \\
\hline Lower Jaw & 15 & 21 & 12 & 6 & 31 & 11 & 0 \\
\hline Total & $\mathbf{2 6}$ & $\mathbf{3 2}$ & $\mathbf{1 3}$ & $\mathbf{1 2}$ & $\mathbf{3 9}$ & $\mathbf{1 9}$ & $\mathbf{1}$ \\
\hline
\end{tabular}

Table 3: Marginal bone loss from baseline (implant placement) to all evaluated timepoints

\begin{tabular}{|c|c|c|c|c|c|c|c|c|c|c|}
\hline & \multicolumn{10}{|c|}{ Marginal bone loss at prosthetic delivery } \\
\hline Treatment & Total & Missing & $\begin{array}{l}\text { Total } \\
\text { valid }\end{array}$ & Mean & Std & Min. & $\begin{array}{c}1 . \\
\text { Quartile }\end{array}$ & Median & $\begin{array}{c}3 . \\
\text { Quartile }\end{array}$ & Max \\
\hline SC & 49 & 2 & 47 & 0.739 & 0.606 & -0.41 & 0.34 & 0.64 & 1.09 & 2.78 \\
\hline FDP & 22 & 1 & 21 & 0.534 & 0.425 & -0.11 & 0.11 & 0.56 & 0.86 & 1.43 \\
\hline \multirow[t]{2}{*}{ Total } & 71 & 3 & 68 & 0.676 & 0.561 & -0.41 & 0.32 & 0.60 & 0.96 & 2.78 \\
\hline & \multicolumn{10}{|c|}{ Marginal bone loss at 1 year follow-up } \\
\hline Treatment & Total & Missing & $\begin{array}{l}\text { Total } \\
\text { valid }\end{array}$ & Mean & Std & Min. & $\begin{array}{c}1 . \\
\text { Quartile }\end{array}$ & Median & $\begin{array}{c}3 . \\
\text { Quartile }\end{array}$ & Max \\
\hline SC & 49 & 3 & 46 & 0.668 & 0.613 & -0.45 & 0.19 & 0.58 & 1.01 & 2.33 \\
\hline FDP & 22 & 3 & 19 & 0.438 & 0.425 & -0.11 & 0.04 & 0.38 & 0.83 & 1.39 \\
\hline \multirow[t]{2}{*}{ Total } & 71 & 6 & 65 & 0.601 & 0.571 & -0.45 & 0.15 & 0.53 & 0.86 & 2.33 \\
\hline & \multicolumn{10}{|c|}{ Marginal bone loss at 3 year follow-up } \\
\hline Treatment & Total & Missing & $\begin{array}{l}\text { Total } \\
\text { valid }\end{array}$ & Mean & Std & Min. & $\begin{array}{c}1 . \\
\text { Quartile }\end{array}$ & Median & $\begin{array}{c}3 . \\
\text { Quartile }\end{array}$ & Max \\
\hline SC & 49 & 6 & 43 & 0.734 & 0.772 & -0.44 & 0.18 & 0.55 & 1.09 & 3.21 \\
\hline FDP & 22 & 1 & 21 & 0.638 & 0.616 & -0.56 & 0.35 & 0.60 & 1.13 & 1.75 \\
\hline Total & 71 & 7 & 64 & 0.702 & 0.721 & -0.56 & 0.26 & 0.59 & 1.11 & 3.21 \\
\hline
\end{tabular}


Table 4: Investigated prognostics factors on marginal bone loss

\begin{tabular}{|c|c|c|c|}
\hline Variable & estimate & $95 \% \mathrm{Cl}$ & P-value \\
\hline Marginal bone level at implantation & -0.695 & {$[-1.034,-0.356]$} & $<0.001$ \\
\hline center (Zurich/Freiburg) & 0.152 & {$[-0.236,0.541]$} & 0.441 \\
\hline jaw (maxilla/mandible) & -0.390 & {$[-0.804,0.024]$} & 0.065 \\
\hline SC / FDP & -0.326 & {$[-0.818,0.165]$} & 0.193 \\
\hline Implant diameter 4.5 relativ to 4.0 & 0.065 & {$[-0.195,0.325]$} & \multirow{2}{*}{0.450} \\
\hline Implant diameter 5.5 relativ to 4.0 & 0.275 & {$[-0.153,0.703]$} & \\
\hline Implant length 10 relativ to 8 & -0.156 & {$[-0.474,0.160]$} & \multirow{3}{*}{0.064} \\
\hline Implant length 12 relativ to 8 & 0.226 & {$[-0.183,0.635]$} & \\
\hline Implant length 14 relativ to 8 & 0.282 & {$[-0.994,1.559]$} & \\
\hline
\end{tabular}

Table 5: Comparison of the Plaque frequency at implants and adjacent teeth ( $\Delta$ shows the mean difference to baseline ( 0 month) in patients with both measurements. The p-values at the bottom refer to a Wilcoxon signed-rank test applied to the differences comparing 36 months with baseline)

\begin{tabular}{|c|c|c|c|c|c|c|}
\hline & \multirow{2}{*}{$\begin{array}{l}\text { Total } \\
\text { valid }\end{array}$} & \multicolumn{4}{|c|}{ Plaque in $\%$} & \multirow{2}{*}{$\begin{array}{l}\text { Signed- } \\
\text { rank }\end{array}$} \\
\hline & & Implants & $\Delta$ & Teeth & $\Delta$ & \\
\hline 0 month & 63 & $11.8 \pm 25.8$ & & $21.0 \pm 25.5$ & & $p=0.0025$ \\
\hline 6 months & 62 & $22.1 \pm 30.8$ & 10.1 & $37.5 \pm 32.9$ & 16.1 & $\mathrm{p}<0.0001$ \\
\hline 12 months & 61 & $21.6 \pm 29.8$ & 0.9 & $41.6 \pm 32.6$ & 19.9 & $\mathrm{p}<0.0001$ \\
\hline 24 months & 60 & $20.1 \pm 27.9$ & 7.8 & $47.3 \pm 30.5$ & 25.2 & $\mathrm{p}<0.0001$ \\
\hline 36 months & 57 & $20.8 \pm 26.7$ & 8.5 & $41.4 \pm 29.3$ & 19.3 & $\mathrm{p}<0.0001$ \\
\hline $\begin{array}{l}\text { Signed-rank } \\
\text { test (0 vs. } 36 \text { ) }\end{array}$ & & & $p=0.022$ & & $\mathrm{p}<0.0001$ & \\
\hline & & & & & & \\
\hline
\end{tabular}


Table 6: Comparison of the mean Probing depth around implants and adjacent teeth ( $\Delta$ shows the mean difference to baseline ( 0 month) in patients with both measurements. The p-values at the bottom refer to a Wilcoxon signed-rank test applied to the differences comparing 36 months with baseline)

\begin{tabular}{|c|c|c|c|c|c|c|}
\hline & Total & & PD in & $\mathrm{nm}$ & & Signed- \\
\hline & valid & Implants & $\Delta$ & Teeth & $\Delta$ & rank test \\
\hline 0 month & 63 & $2.71 \pm 0.62$ & & $2.53 \pm 0.44$ & & $\mathrm{p}=0.111$ \\
\hline 6 months & 62 & $3.24 \pm 0.59$ & 0.56 & $2.46 \pm 0.48$ & -0.06 & $\mathrm{p}<0.0001$ \\
\hline 12 months & 61 & $3.47 \pm 0.67$ & 0.78 & $2.43 \pm 0.52$ & -0.10 & $\mathrm{p}<0.0001$ \\
\hline 24 months & 60 & $3.60 \pm 0.66$ & 0.89 & $2.46 \pm 0.45$ & -0.06 & $\mathrm{p}<0.0001$ \\
\hline 36 months & 57 & $3.52 \pm 0.66$ & 0.81 & $2.54 \pm 0.57$ & 0.02 & $\mathrm{p}<0.0001$ \\
\hline $\begin{array}{l}\text { Signed-rank } \\
\text { test (0 vs. } 36)\end{array}$ & & & $\mathrm{p}<0.0001$ & & $\mathrm{p}=0.80$ & \\
\hline & & & & & & \\
\hline
\end{tabular}

Table 7: Comparison of Bleeding on probing frequency at implants and adjacent teeth ( $\Delta$ shows the mean difference to baseline ( 0 month) in patients with both measurements. The $\mathrm{p}$-values at the bottom refer to a Wilcoxon signed-rank test applied to the differences comparing 36 months with baseline)

\begin{tabular}{|c|c|c|c|c|c|c|}
\hline & \multirow{2}{*}{$\begin{array}{l}\text { Total } \\
\text { valid }\end{array}$} & \multicolumn{4}{|c|}{ BoP \% } & \multirow{2}{*}{$\begin{array}{l}\text { Signed- } \\
\text { rank test }\end{array}$} \\
\hline & & Implants & $\Delta$ & Teeth & $\Delta$ & \\
\hline 0 month & 63 & $16.8 \pm 27.5$ & & $13.5 \pm 21.9$ & & $\mathrm{p}=0.909$ \\
\hline 6 months & 62 & $43.5 \pm 36.5$ & 26.4 & $29.4 \pm 42.8$ & 16.1 & $\mathrm{p}=0.0052$ \\
\hline 12 months & 61 & $57.5 \pm-32.9$ & 41.8 & $34.0 \pm 48.9$ & 20.5 & $\mathrm{p}=0.0001$ \\
\hline 24 months & 60 & $48.9 \pm 36.3$ & 31.7 & $30.8 \pm 38.9$ & 17.1 & $\mathrm{p}=0.0013$ \\
\hline 36 months & 57 & $40.8 \pm 32.9$ & 23.5 & $23.2 \pm 33.0$ & 9.6 & $\mathrm{p}=0.0045$ \\
\hline $\begin{array}{l}\text { Signed-rank } \\
\text { test (0 vs. } 36 \text { ) }\end{array}$ & & & $\mathrm{p}<0.0001$ & & $\mathrm{p}=0.137$ & \\
\hline & & & & & & \\
\hline
\end{tabular}


Table 8: Mean Marginal soft tissue level at implant and adjacent teeth sites. ( $\Delta$ shows the mean difference to baseline ( 0 month) in patients with both measurements. The $p$-values at the bottom refer to a Wilcoxon signed-rank test applied to the differences comparing 36 months with baseline)

\begin{tabular}{|l|c|c|c|c|c|}
\hline & Total & \multicolumn{4}{|c|}{ Marginal soft tissue level in mm } \\
\cline { 3 - 6 } & valid & Implants & $\Delta$ & Teeth & $\Delta$ \\
\hline 0 month & 63 & $0.70 \pm 0.33$ & & $1.22 \pm 0.80$ & \\
\hline 6 months & 62 & $0.70 \pm 0.48$ & -0.020 & $1.16 \pm 0.77$ & -0.071 \\
\hline 12 months & 61 & $0.71 \pm 0.24$ & 0 & $1.22 \pm 0.72$ & -0.029 \\
\hline 24 months & 60 & $0.66 \pm 0.27$ & -0.033 & $1.23 \pm 0.67$ & 0.004 \\
\hline 36 months & 57 & $0.65 \pm 0.27$ & -0.025 & $1.21 \pm 0.59$ & 0.057 \\
\hline $\begin{array}{l}\text { Signed-rank } \\
\text { test (0 vs. 36) }\end{array}$ & & & $\mathrm{p}=0.526$ & & $\mathrm{p}=0.047$ \\
\hline & & & & & \\
\hline
\end{tabular}

Table 9: Mean Clinical attachment level around implants and adjacent teeth. ( $\Delta$ shows the mean difference to baseline ( 0 month) in patients with both measurements. The p-values at the bottom refer to a Wilcoxon signed-rank test applied to the differences comparing 36 months with baseline)

\begin{tabular}{|l|c|c|c|c|c|}
\hline & Total & \multicolumn{4}{|c|}{ CAL in mm } \\
\cline { 3 - 6 } & Valid & Implants & $\Delta$ & Teeth & $\Delta$ \\
\hline 0 month & 63 & $2.76+-0.68$ & & $3.14+-0.85$ & \\
\hline 6 months & 62 & $2.88+-0.96$ & 0.139 & $3.08+-0.85$ & -0.077 \\
\hline 12 months & 61 & $3.05+-0.92$ & 0.258 & $3.11+-0.82$ & -0.053 \\
\hline 24 months & 60 & $2.81+-1.09$ & -0.029 & $3.15+-0.75$ & 0.002 \\
\hline 36 months & 57 & $2.78+-1.00$ & -0.029 & $3.19+-0.74$ & 0.118 \\
\hline $\begin{array}{l}\text { Signed-rank } \\
\text { test (0 vs. 36) }\end{array}$ & & & $\mathrm{p}=0.523$ & & $\mathrm{p}=0.052$ \\
\hline & & & & & \\
\hline
\end{tabular}




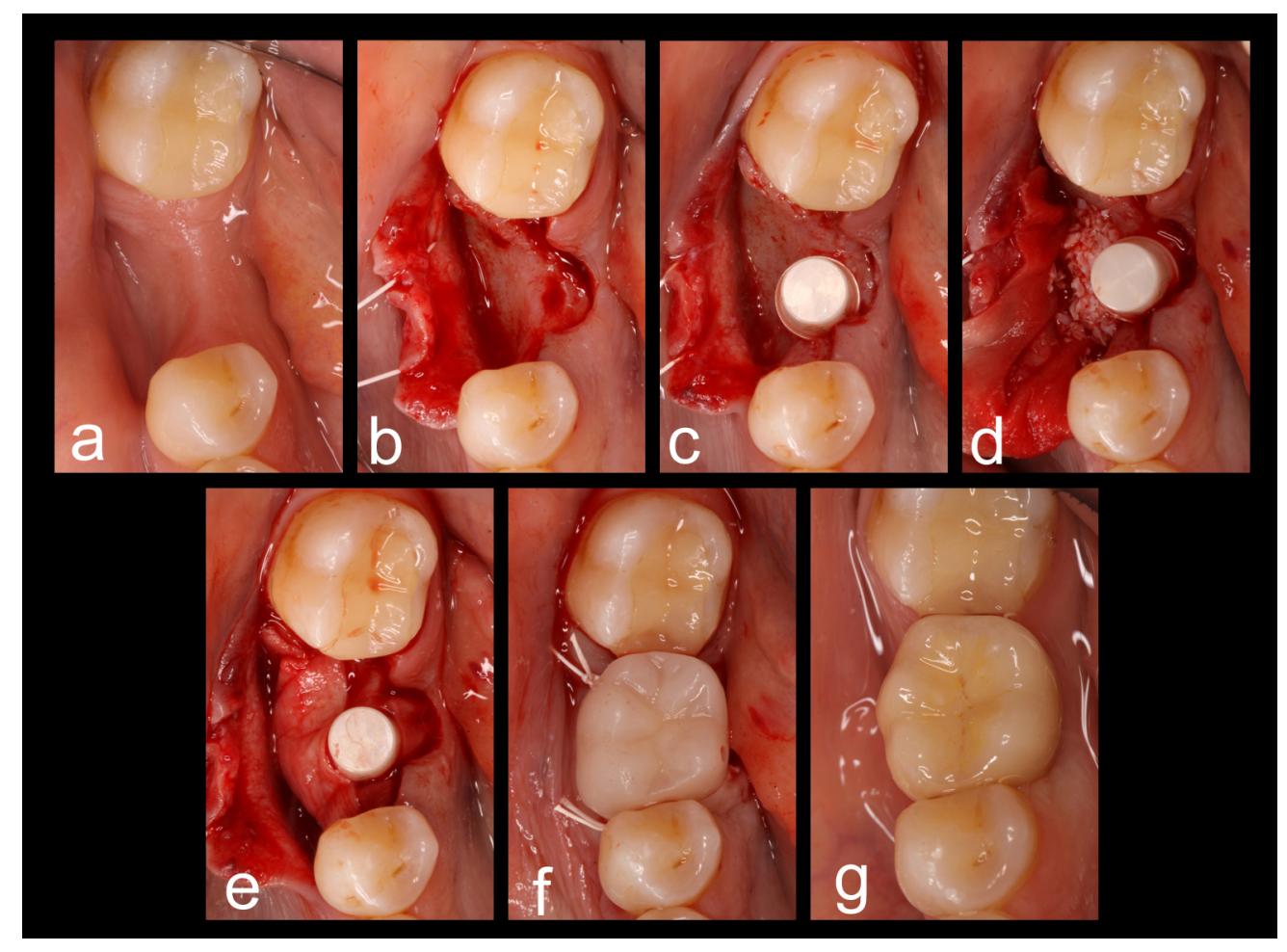

Figure 1

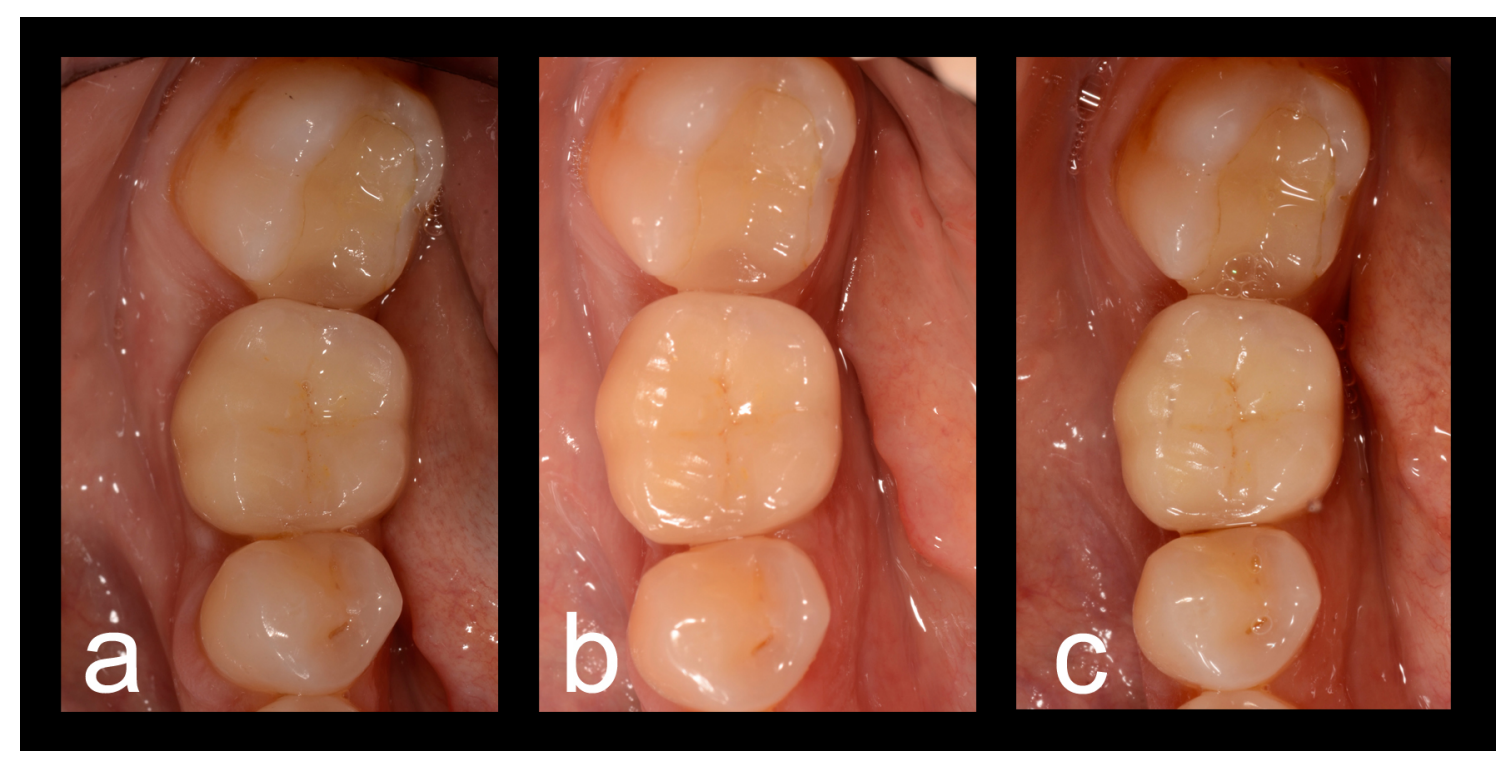

Figure 2 


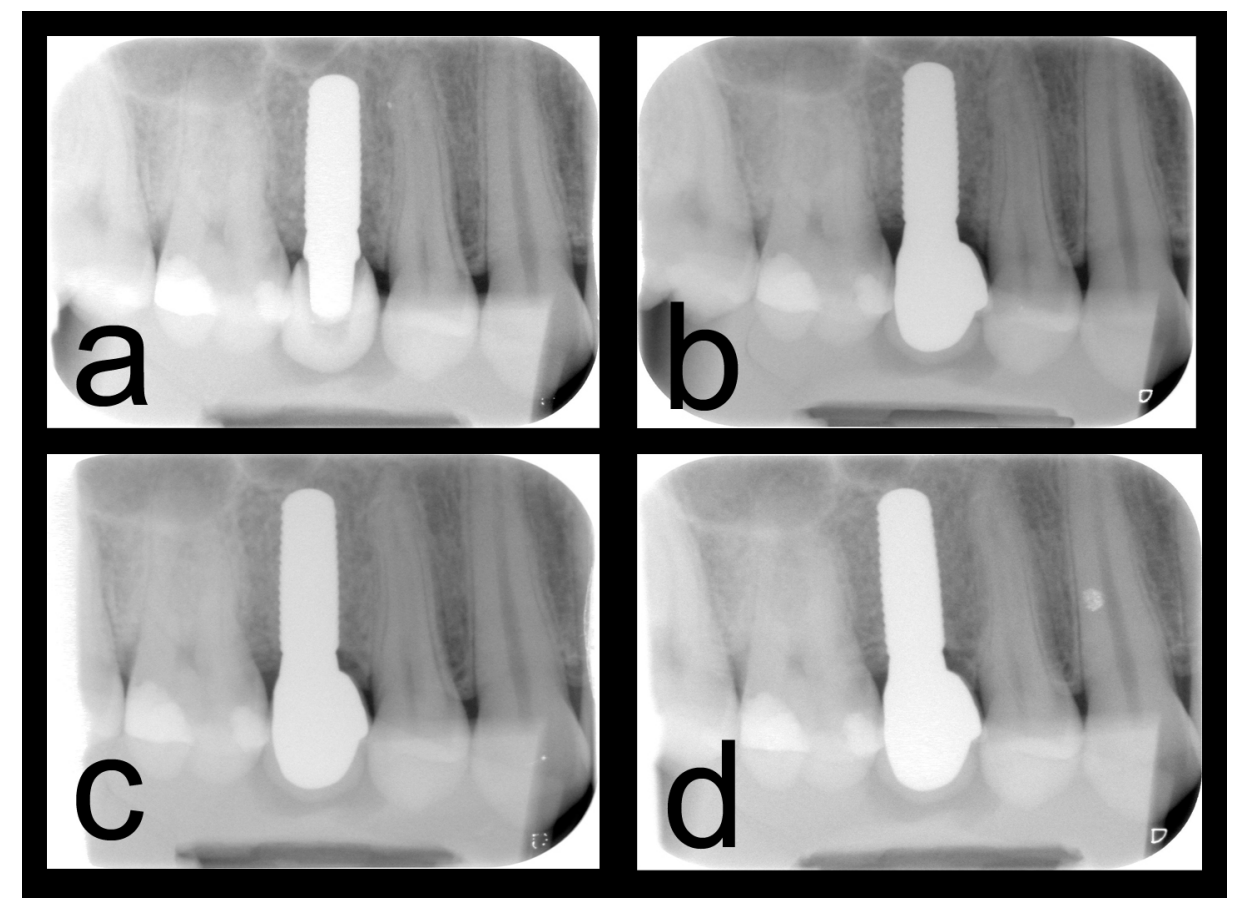

Figure 3

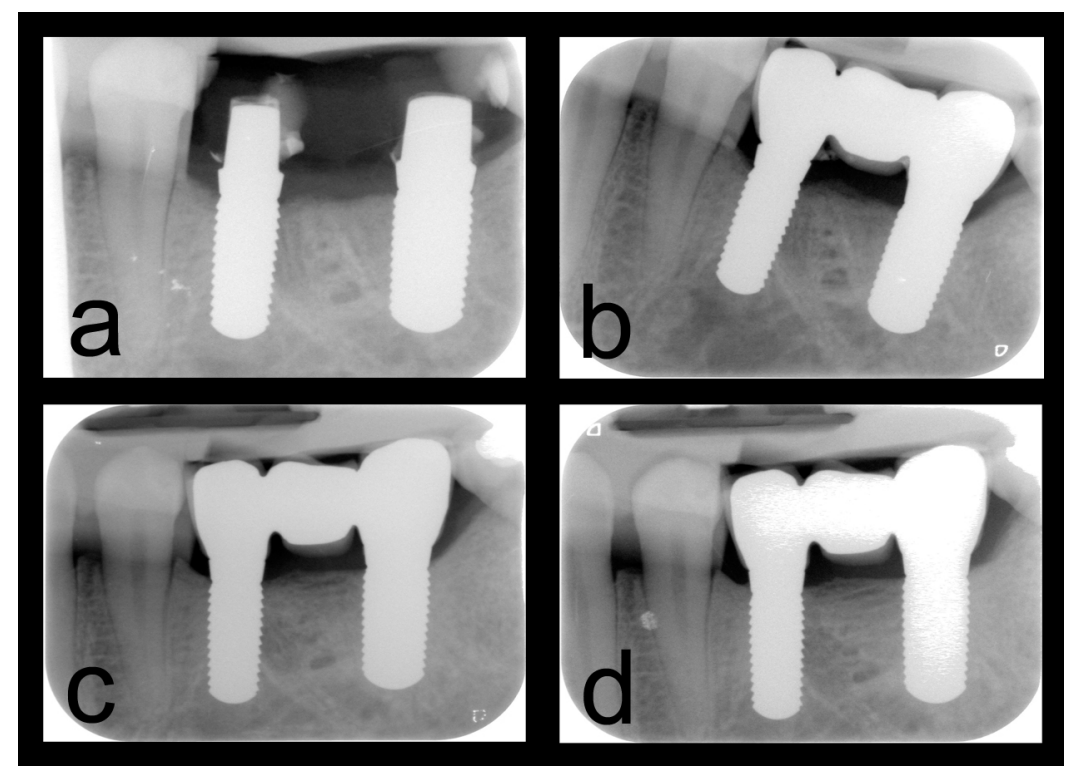

Figure 4 